\title{
Perception and Readiness towards Indian Ayurvedic Medicine Acceptance to Combat COVID-19 Outbreak: A Multigroup Analysis in PLS Path Modelling
}

\author{
Research Article
}

\section{Shathees Baskaran ${ }^{*}$, Kesavan Nallaluthan ${ }^{2}$, \& Velan Kunjuraman ${ }^{3}$}

1. Azman Hashim International Business School, Universiti Teknologi Malaysia, Johor, Malaysia. 2. Faculty of Management \& Economics, Universiti Pendidikan Sultan Idris, Tanjong Malim, Perak, Malaysia. 3. Faculty of Hospitality, Tourism \& Wellness, Universiti Malaysia Kelantan.

\begin{abstract}
Introduction-COVID-19 has come to us as a danger without a cure. Ayurvedic Medicine is seen to have the potential to be an alternative solution in curing COVID-19. Hence, the research aims to empirically investigate the adoption of Ayurvedic Medicine as an alternative cure for COVID-19 among the users and non-users. Methods-The research employed a quantitative research approach using a survey involving adults aged more than 18 years old. A convenient sampling method was chosen for this research. The collected data was analyzed by employing PLS-SEM and PLS-SEM MGA. Results - The results indicated that there is no significant difference between users and nonusers of Ayurvedic medicine. All hypotheses formulated investigating Ayurvedic medicine beliefs, attitude, perception, and satisfaction in considering it as a Potential Alternative for COVID-19 were retained. Conclusion This study has provided new insights in understanding the possibilities of using Ayurvedic medicine in curing COVID-19 and welcoming the medical practitioners of clinical research to identify the technical properties of Ayurvedic Medicine to be considered as an alternative for COVID-19 and many other existing and future diseases. The novelty of this study is two-fold. First, this is a pioneer study attempting to understand the public's view in considering Ayurvedic medicine as an alternative in combating COVID-19. Second, the conceptual model presented in this study to bridge the critical knowledge gap of the Ayurvedic Medicine phenomenon is neither formulated nor tested empirically in previous studies, locally or perhaps globally, therefore stands out as an original incremental contribution in ayurvedic medicines perception.
\end{abstract}

Key Words: Ayurvedic, COVID-19, Belief, Perception, Attitude, Satisfaction.

\section{Introduction}

Ayurvedic Medicine is popular among the Indian community all around the world and India is the mother for its birth. In terms of worldwide fame, Ayurvedic Medicine is the number three in position and eighty percent of the world population utilize traditional medicine as primary health care (1). As compared to modern medicine, Ayurvedic Medicine continuously flourished in terms of its use among the local community who has faith in it. Ayurvedic Medicine derives from plants that contain medicinal values and contain various phytochemicals. These phytochemicals help to relieve diseases by removing metabolic toxins from our body, boost up our immunity and purify the blood (1). Thus, Ayurvedic Medicine could have the potential to be a remedy for many diseases depending on their level of complications.

* Corresponding Author:

Shathees Baskaran

Azman Hashim International Business School,

T-08, Level 03-10-02,

Universiti Teknologi Malaysia,

81310 Johor Bahru, Johor, Malaysia.

Email Id: shathees@utm.my
In the past four decades, the human population has experienced and witnessed the eradication of life due to many threatening diseases. Among the famous are smallpox, tuberculosis, Zika, HIV/AIDS, and Ebola have emerged to disturb human lives. Ironically, as cautioned by (2), 'increased human longevity has been countered by the decreased quality of life' (p. 73). This is a real challenge that human is currently facing with a hope that modern medicine would provide solutions and safeguard the human quality of life. Many scientists and philosophers believed that the problems we faced nowadays concerning health and disease cannot be managed merely with the help of modern biomedicine. Millions of dollars and thousands of scientists are committed to developing new vaccines and medications for many diseases and often spent many years to be approved for general use. Merely depending on modern medicine to treat illnesses is no longer a wise decision and more new approaches are needed. As a result, new approaches to diseases prevention, techniques for treatment, integrative medicine, holistic health, and wellness are being considered and encouraged. Therefore, Ayurvedic Medicine is a timely solution and its knowledge and wisdom of Ayurveda are being valued and appreciated (3).

Indian medicine has a long history and in Malaysia, it has been documented by Colley (4). Indian medicine meant by Colley was Ayurvedic Medicine and 
was widely practiced by the Indian community in Malaysia and other parts of the world. Ayurvedic Medicine benefits to the overall health of human life are evident and need to be explored further. Ayurvedic Medicine is not just materia medica or herbal medicine but its contributions to human health continuously documented by the current researchers. Therefore, more research on Ayurvedic Medicine should be done to explore its contributions and benefits to mankind.

\section{Problem Statement}

Based on the literature, Ayurveda is a holistic system of healing that has a tradition of 3000 years old. Kerala and Ayurveda are synonymous with each other, as it is the only place on earth where Ayurveda is practiced with absolute authenticity and dedication. This ancient Indian system of medicine has proved to be not only the cure for illness but also the 100 percent natural way to perfect health. The methods of Ayurveda are unique and universal. Instead of treating the symptoms of a disease, it treats the individual and caring is given for the entire body. Ayurveda medicines are purely natural and free of side effects (5).

Various diseases are continuously emerging and becoming a challenge for the human to live healthily. Several diseases that emerged (see Table 1) in the last decades which threatened the world were identified by the World Health Organization. Millions of lives were lost due to these diseases and modern medicine was the main solution. However, depending merely on modern medicine is not always a good strategy for the people as it has some limitations in terms of time constraints, experts, and clinical experiments. Recently, the world experienced the most dangerous disease outbreak called Novel Coronavirus or popularly known as COVID-19 which was originated from the city of Wuhan, China. Almost all sectors were seriously affected by this COVID-19 and several countries announced a partial and full lockdown including Malaysia.

Table 1: Global Outbreak in Human History

\begin{tabular}{|c|c|c|c|c|c|}
\hline Year & Diseases & $\begin{array}{l}\text { Country } \\
\text { of } \\
\text { Origin }\end{array}$ & $\begin{array}{l}\text { Infecte } \\
\quad \text { d }\end{array}$ & Deaths & $\begin{array}{c}\text { Fatality } \\
(\%)\end{array}$ \\
\hline 1967 & MARBURG & Uganda & 590 & 478 & 81 \\
\hline 1976 & EBOLA & DRC & 33,687 & 14,693 & 44 \\
\hline 1999 & NIPAH & Malaysia & 496 & 265 & 53 \\
\hline 2002 & SARS & China & 8,098 & 774 & 10 \\
\hline 2003 & $\begin{array}{c}\text { H5N1-BIRD } \\
\text { FLU }\end{array}$ & China & 861 & 455 & 53 \\
\hline 2009 & $\begin{array}{l}\text { A(H1N1) } \\
\text { pdm09 }\end{array}$ & $\begin{array}{l}\text { US and } \\
\text { Mexico }\end{array}$ & $\begin{array}{c}1 \\
\text { million }\end{array}$ & $\begin{array}{l}123,000- \\
203,000\end{array}$ & $\begin{array}{c}\text { Below } \\
0.01\end{array}$ \\
\hline 2012 & MERS & $\begin{array}{l}\text { Saudi } \\
\text { Arabia }\end{array}$ & 2,494 & 858 & 35 \\
\hline 2013 & $\begin{array}{l}\text { H7N9-BIRD } \\
\text { FLU }\end{array}$ & China & 1,568 & 616 & 39 \\
\hline Yearly & $\begin{array}{c}\text { Seasonal } \\
\text { flu }\end{array}$ & - & 1 billion & $\begin{array}{l}290,000- \\
650,000\end{array}$ & $\begin{array}{c}\text { Below } \\
0.01\end{array}$ \\
\hline $\begin{array}{l}\text { On- } \\
\text { going }\end{array}$ & 2019-nCov & Global & $\begin{array}{c}25,405 \\
556^{*}\end{array}$ & $849,383^{*}$ & $3^{*}$ \\
\hline
\end{tabular}

To date, COVID-19 has come to all of us as a danger without a cure. Modern science is working hard to find a cure. Nevertheless, traditional medications that were proven to be efficient in the past are no lesser in providing sufficient help in finding the cure. Ayurvedic Medicine or Ayurveda certainly can contribute to new drug discovery. This potential was highlighted by Rastogi, Pandey, and Singh (6) who mentioned that "Ayurveda has enough potential and possibilities to be employed both for prevention and treatment of COVID-19" (p.3). Many classical Ayurvedic drugs have the potential to be included in modern therapeutics. Ayurvedic drugs can serve as very good adjuvants in many chronic and difficult to treat conditions like cancer, diabetes, asthma, and obesity (2). A study by Kritikaa and Paul Antony (5) indicates that the majority of the health tourists in India would like to recommend Ayurveda treatment to others. Ayurvedic Medicine, therefore, has the potential to cure illnesses faced by humans nowadays. Consequently, this study aims to examine general perception and readiness towards Indian Ayurvedic Medicine consumption acceptance to combat the COVID-19 outbreak in the world.

\section{Research Objectives}

The purpose of this research is to examine perception and readiness towards Indian Ayurvedic medicine consumption acceptance to combat the COVID-19 outbreak. More specifically, this research aims to investigate the associations between Ayurvedic Medicine beliefs, attitude, perception, and satisfaction, as a potential alternative for COVID-19. Accordingly, the following research objectives are designed:

RO1. there is no significant difference between users and non-users of Ayurvedic Medicine.

$\mathrm{RO} 2$. there is a relationship between Ayurvedic Medicine beliefs and perceptions of Ayurvedic Medicine.

RO3. there is a relationship between attitude towards Ayurvedic Medicine and perceptions of Ayurvedic Medicine.

RO4. there is a relationship between perceptions of Ayurvedic Medicine and satisfaction on Ayurvedic Medicine.

RO5. there is a relationship between satisfaction on Ayurvedic Medicine and Ayurvedic Medicine as a Potential Alternative for COVID-19.

\section{Literature review \\ Theoretical Underpinnings}

This section discusses the literature in the field. Complementary and Alternative Medicine (CAM) provides a variety of treatment modalities not protected by modern evidence-based medicine (EBM) Additional medicine is used alongside EBM, whereas alternative medicine replaces EBM altogether (Tabish, 2008). Therefore, traditional Chinese medicine (TCM) in China Mainland, Ayurveda in India, conventional Korean medicine in Korea, and TCM in Japan are among the major CAM procedures in Asia. Siddha 
Medicine is accompanied by a mainstream form of medicine rooted in the ancient Tamil Nadu. In modern Central Asia, the Persian-Arab form of conventional medicine known as Unani, used in Mughal India, is practiced (7). CAM is generally recognized in virtually all in Asia, but the absence of medical information based on facts, lack of research, and clinical trial-related trials in CAM have contributed to general approval drifting in using them. The widespread popularity of word of mouth and social media in general and in patients with both acute and chronic illnesses, however, assured a 'safer' CAM-relevance, led to a massive surge in the use of this practice (8).

\section{Ayurvedic medicine}

Ayurvedic treatment is one of the oldest medical treatments in the country which originated from India. CAM treatment system in the United States involves alternative and therapeutic treatment. Ayurveda aims to merge and control the body, mind, and spirit. This is known to lead to illness prevention and good wellbeing. If poorly used or without a trained teaching guide, all of these things may be harmful (9). Ayurveda's premise is that there are balanced connections within the mind and body (10). The value of understanding of his body and mind and of working in constant communication with nature allows the individual to learn. Ayurvedic literature therapies include age-related treatments of illness for which conventional treatment may not provide appropriate medication, such as memory impairment, osteoporosis, diabetic lesions. Footprints focused on the active ingredient or key compounds can formulate ayurvedic formulations (11).

Ancient Indian medicine aims to balance the patient and his surroundings by creating an optimal atmosphere for man's well-being. The entire Ayurvedic theory is rooted in the Five Great Elements concept. The five components are the space, air, fire, water, and earth. Within Ayurvedic medicine today only the concept of well- being and disease prevention is retained (12). When handling the vital infrastructure in an organization correctly, internal deterioration and disease periods can be minimized. It is achieved by balanced eating, learning and functioning habits, and natural healthcare.

\section{Ayurvedic medicine as a potential treatment for COVID-19}

As researchers in medicine have recommended that the body's immune response will be improved because the global attempt to find a treatment for COVID-19 has been made (13). Wynn and Fougère (14) claim that ayurvedic herbs like tulsi, cinnamon, black pepper, shunthi (dry ginger), raisins, and daily yoga will help improve the physical protection from harmful viruses. Besides, specialists from Ayurveda who describe specific COVID-19 preparations and now have homeopathic drugs to improve immunity.

This problem has attracted considerable attention in the literature. Therefore, Ayurveda has sufficient potential and opportunities to prevent and treat COVID-19. This is an important chance to learn and generate credible evidence (15). It is critical that Ayurveda's contribution to tackling the COVID-19 challenge in Malaysia should not continue to be limited and should be regarded as the extension of healthcare and biomedical system support services. Implementation of the proposed action would undoubtedly provide evidence-based perspectives to expand Ayurveda's reach beyond preventive healthcare and non-communicable disease treatment. AYUSH system from India was warned all over the country that it was called to serve the worldwide nations at any time. AYUSH medical services are also ready to be converted in times of need into quarantine facilities. From this standpoint, it may be very beneficial to the nation to implement the proposed intervention plan within AYUSH health facilities.

\section{Ayurvedic medicine beliefs}

As far as Ayurveda is concerned, two major opposite positions can be found (16): (a) modern Ayurvedic supporters argue that it was once an objective medical method where philosophical and theological speculations are merely interpolations, exogenous to the framework or (b), conventional Ayurvedic supporters assert that philosophical and metaphysical components are still central to the Ayurveda. However, these positions should not preclude each other. Acceptance and desire for Ayurveda are on the west, though over 2000 published journal papers in the Indian Internet Archive DHARA are now accessible in over 2500 online publications on Ayurvedic therapies in PubMed. Spirituality is assumed to be the main attracting factor for Ayurveda's popularity (17). There is, however, no empirical data concerning its impact on the dissemination and adoption of modern hybrid Ayurvedic through religious and metaphysical elements (18). This is striking because spirituality, it has already been discussed in the areas of neurobiology, particularly in chronic diseases (19), and especially in research on the quality and quality of life. Nonetheless, non-western CAM attractors have lately been debating and are starting to work in the fields of culture and spirituality (20). The comparatively late understanding of spiritual issues of CAM may be attributed to the effect on the medical community, and particularly on research efforts conducted of CAM, of the philosophy of Evidence-Based Medicine (EbM). Recently, following several evidences gaps in CAM research, researchers became conscious of the need to undertake research that focused not only on specific evidence but also on unspecific or contextual aspects (CAM-related aspects). It is in no way in contrast with EbM as the combination of (a) the best evidence with (b) professional expertise and (c) patient principles were described by a creator as EbM. Nonetheless, up to now, scientific science has primarily concentrated on the two preceding factors. 


\section{Attitudes towards ayurvedic medicine}

The accounts of discomfort, illness, impairment, and recovery responses affect perceptions, opinions, and aspirations on the various facets of their condition and their capacity to copy and the health system (21). Any people often have myths and assumptions about the pain that impairs their coping ability. Maladaptive beliefs are often not factual but emotional, leading to a sense of helplessness and a low degree of self-efficacy (22). As a result, a considerable percentage of pain victims consider themselves greatly impaired by their failure to respond to severe pain and impairment. Any people can still have a deep conviction that their suffering will be "healed," as a barrier to counseling activation and teaching in techniques to selfmanage. The beliefs of the patient determine their disease response and their strategies for dealing with it. Physicians may be irritated by misunderstandings by respecting these beliefs and their patients. It is more relevant to learn what type of patient has an infection than the sort of disorder that a patient has; Sir William Osier correctly points out that. Patient attitudes are an important early step in patient care improvement. Patients' approach to Ayurvedic Medicines is highly relevant to regulators. With a growing demand for Ayurvedic medicines, the development, selling, and advertisement of such medicines are proportionate (23). In this sector of Ayurvedic Medicines, however, there is a significant knowledge deficit. Nevertheless, certain patients have good confidence and find them healthy with most Ayurvedic medicines.

\section{Satisfaction on ayurvedic medicine}

The happiness of the customer is based upon perceived success and the efficiency and perceived principles of the goods and services provided following the preferences of the patients (24). The patient will be dissatisfied if the hospitals fail to provide the services to meet the expectations of the patient. The patients are happy, on the other side, as their expectations are fulfilled when in hospitals. Though Ayurvedic government agencies provide free care, hospital administrations will do more to have higher values to attract and maintain Ayurvedic patients. The patients come to ayurvedic establishments to satisfy their observations, values, and thoughts, and advice. The hospital managers will also have higher quality medications, clinics, and other facilities to fulfill their clients' varied needs. The consumer service and loyalty are two significant interrelated domains, according to Armstrong et al. (24). Patients are really happy and commitment is motivated by pleasure. Customer satisfaction tests the expected retention of consumers and their ability to continue business with the brand. The consumers remain faithful when their needs are met, demonstrated by Armstrong et al. (24). Loyal consumers in the ayurvedic industry are even more valuable than happy customers. When regular customers/patients regularly visit each other, suggest therapies, and distribute the favorable word of mouth ads to others and giving Ayurveda more importance to the industry (25).
Patient satisfaction is a significant metric used to assess the quality of health care facilities in Ayurvedic medicine. The idea of satisfaction of patients is being highly popular in the Ayur Vedic Medicine healthcare industry. Patient satisfaction is based on timely treatment and the provision of a professional health care system in an effective and patient-oriented manner. Improved customer satisfaction with Ayurvetic Medicine's healthcare facilities contributes to increased service repurchase, a favorable word of mouth, and other beneficial results for Ayurvesic Medicine among faithful healthcare customers, according to previous studies.

\section{Perception of Ayurvedic medicine}

Ayurvedic medicine has several complications that are assumed to arise from the causes of patients or physicians and they are often studied separately. The mixture of viewpoints in this research allowed patients to link their functional experiences to many facets of ayurvedic therapy. The doctor should not put the viewpoint of Ayurvedic medicine on the shelf by accommodating the opinions of the patient but should address the beliefs of the patient on an equal basis with the physician's beliefs. However, by engaging with them one cannot recognize the thoughts or opinions of patients. It is not necessary to communicate only who thinks that he knows others' views: but the person that treats the other as equal must be aware of the other's perceptions. The concept of patient sovereignty cannot be followed without such information. Much was written regarding concern for the shared expectations and preferences of patients, but little was given to the issue of not taking the chance of disclosing patients' views and beliefs, and needs. The findings of this science-in-humanities work indicate that the experiences of patients of illnesses and in the therapeutic phase are highly significant influences. Within the sense of patient expectations, all clinical choices, minor or important, should be made. The patient's understanding framework for disease and disease is different from but no less important for the physician. However, in ayurvedic medicine in general, we are not accustomed to concerns and issues from the patient and were not educated in these. We see it because we have been trained; we sometimes do not recognize the opinions and values of the patients. In reality, medical models and hypotheses have consequences for our daily feelings, decisions, and behavior. For the outcomes of the consultation, empirically validated awareness of patient expectations that contribute to professional considerations regarding their impact on medical practice and study. The present perceived patient model gives us a new approach to well-known clinical problems and offers an insight into the significant aspects of the patient's understanding of his or her health.

\section{Research model and hypotheses}

The use of any medicine is subject to evidencebased rational thinking. Hence, safety, efficacy, and action mechanisms of any traditional medicinal systems 
including Ayurveda have remained an unavoidable obligation to the users or non-users of the medicine. The users of Ayurvedic medicine are generally convinced by the level of satisfaction gained from its benefits as reported by several previous studies (e.g. (26); (27); (28); (29); (30)). On the contrary, the non-users of Ayurvedic medicine indicated that issues such as unavailability of dependable Ayurvedic physician, slow action, and longer duration of the treatment to be among many other reasons for their limited interest in using Ayurvedic medicine. However, these non-users are willing to use the Ayurvedic medicine considering that Ayurvedic medicine is much cheaper in comparison to modern medicine, increased scientific validation and acceptation, increased accessibility to establishments providing such facility and shorter duration of treatment ((31); (32)). Nevertheless, several studies (e.g., (26); (31); (33)) reported that there is no difference between users and non-users, especially for their source of knowledge for Ayurveda. Based on these arguments, the following hypothesis was formulated:

\section{- H1: There is no significant difference between users and non-users of Ayurvedic Medicine.}

Belief and perception are two words that refer to mental states or conditions that influence how see things around. Perception is how sensory information to notice something or how you understand something. Belief is a strong conviction or acceptance of something. The key difference between perception and belief is that belief is a strong conviction whereas perception is only the ability to understand or notice something. Therefore, in this study CAM suggests two predictors for the intention to use Ayurvedic medicine. The first indicator is known as users' and non-users' beliefs which can be defined as the amount of positive or negative appraisal of their perception of Ayurvedic medicine. Users' beliefs show that they made a good decision in choosing Ayurvedic medicine which is a greater determinant. Therefore, the intent to use Ayurvedic medicine, which is a result of CAM and the mindset is fairly important compared to other factors, is decided by optimistic beliefs and attitudes together. In a wider range of studies, the importance of user and nonusers' beliefs as one of the main predictors of the purpose of the perception of Ayurvedic medicine was identified. In the same manner, attitudes affect the aim of utilizing Ayurvedic medicine. Hence, it was hypothesized that:

- H2: There is a significant relationship between Ayurvedic Medicine beliefs and perceptions of Ayurvedic Medicine.

The next predictor is named as attitude. It may be described as the user and non-user attitude which as a consumer's perception of Ayurvedic medicine. An aspect analysis of Ayurvedic medicine selection criteria reveals that suggestions were given by users' are one of the main determinants of Ayurvedic medicine selection criteria. Moreover, individual thinking patterns and the influence of social class are the main influencing factors for individuals' behavioral intention towards the use of Ayurvedic medicine. Although the literature reveals several studies (non-Ayurvedic medicine) that endorse attitude as the major determinant of behavioral intention studies may also be found which conclude an insignificant relationship between attitude and perception. Therefore, it is interesting to investigate whether this variable is significant towards perceptions of Ayurvedic medicine. Therefore, based on this discussion, the next hypothesis is:

- H3: There is a significant relationship between attitude towards Ayurvedic Medicine and perceptions of Ayurvedic Medicine.

Customer perception refers to the customer's opinion of Ayurveda medicine. It summarizes how customers feel about Ayurvedic medicine including every direct or indirect experience they've had with traditional medicine. By monitoring customer perception, ayurvedic medicine users can spot common satisfaction and improve the customer journey. This study suggests that customer perception has a significant effect on customer satisfaction of ayurvedic medicine. Therefore, the third hypothesis may be developed as:

- H4: There is a significant relationship between perceptions of Ayurvedic Medicine and satisfaction on Ayurvedic Medicine.

Ayurvedic medicine user satisfaction having high potential for alternative medicine when users found this Ayurvedic medicine unable to cure there sicks. Therefore, dissatisfaction results from the user also give a potential alternative medicine for the nonuser which they learn from the Ayurveda medicine users. Therefore, the fourth hypothesis may be developed as:

- H5: There is a significant relationship between satisfaction on Ayurvedic Medicine and Ayurvedic Medicine as a Potential Alternative for COVID-19.

The following is the conceptual framework proposed for this research:

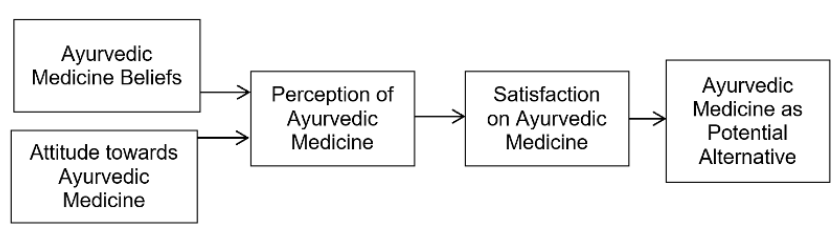

Figure 1 Conceptual framework

\section{Materials and methods \\ Research design}

There are two legitimate ways to investigate an issue which are quantitative and qualitative research 
(34). The ultimate objective of quantitative research is to quantify the relationship between variables (35) as the numbers impress better (36) and the ability to a smaller group of people to generalize and make inferences about the population (37) in line with the traditional assumption of determinism which explains that events are determined by one or more causes (38). Therefore, occupying a larger sample size in predicting and explaining a phenomenon calls for quantitative research (39). This approach also assumes that behaviour is highly predictable and explainable (34).In an attempt to improve the predictive understanding of Ayurvedic Medicine acceptance phenomena, quantitative, descriptive design was proposed in this research since it is more accurate and reliable and it measures specific characteristics of a sample that can be generalized to a population easily and precisely (40).

\section{Measures}

Fraenkel and Wallen (41) argue that a reliable instrument is crucial in the research as it is expected to provide consistent results. As far as instruments concerned, previously developed instruments were adopted, keeping in view the validity and reliability of the measurements with some minor modifications to make it relevant to the research context. The instruments used are as follows:

Table 2: Research Instruments

\begin{tabular}{|l|c|c|}
\multicolumn{1}{|c|}{ Construct } & $\begin{array}{c}\text { Number } \\
\text { of Items }\end{array}$ & \multicolumn{1}{|c}{ Source } \\
\hline $\begin{array}{l}\text { Ayurvedic Medicine Beliefs } \\
\text { (AMB) }\end{array}$ & 7 & Ashraf, et al (42) \\
$\begin{array}{l}\text { Attitude towards Ayurvedic } \\
\text { Medicine (AAM) }\end{array}$ & 12 & Yoshida, et al (1) \\
\hline $\begin{array}{l}\text { Perception of Ayurvedic } \\
\text { Medicine (PAM) }\end{array}$ & 15 & Ashraf, et al (42) \\
\hline $\begin{array}{l}\text { Satisfaction on Ayurvedic } \\
\text { Medicine (SAM) }\end{array}$ & 4 & Yoshida, et al (1) \\
\hline $\begin{array}{l}\text { Ayurvedic Medicine as } \\
\text { Potential Alternative } \\
\text { (AMPA) }\end{array}$ & 3 & Self-developed \\
\hline
\end{tabular}

\section{Population, sample and sampling method}

The research population was made up of Malaysian citizens. Since the COVID-19 pandemic is a nationwide concern, all Malaysians interested to be a participant are included in this research. Therefore, we consider all affected directly or indirectly by the COVID-19 pandemic to be the population.

Neuman (43) explained that sampling involves the process of systematically selecting respondents or cases to be included in the research. Fowler (44) explained that the sample frame is the set of people that has a chance to be selected, given the sampling approach that is chosen and the sampling frame corresponds to the population of the research. It is also equally important that the sampling frame includes almost all members of the population so that it will be a good representative of the population (45). According to Ary, Jacobs, and Razavieh (46), all things being equal, the larger the sample size, the better the representativeness of the population. Although the larger sample size is found to be better than the smaller ones in producing reliable and generalizable results, Roscoe (47) argues that sample size which is larger than 30 and less than 500 should be appropriate for most research. However, Lowhorn (45) indicated that the size of the population, whether narrow or broad is not a concern in research as long as the relevant individual who fits into the study is considered. Malhotra (48) indicate that the sample size depends on the proposed data analysis techniques. However, there is no generally accepted guideline in the literature in determining sample size while using PLS-SEM (49).

Nevertheless, Hair et al (49) suggested a minimum of 100 samples when a research model considers five or fewer constructs 150 to 300 for a research model with seven or fewer constructs, and more than 500 for a research model with a large number of constructs. An alternative method while using PLSSEM suggests that when the research model is reflective, the sample size can be considered independent of the number of indicators (50). Following recommended sample size for a statistical power of $80 \%((51) ;(52))$ at a significant level of $5 \%$ and minimum $\mathrm{R}^{2}$ value of 0.10 by considering the maximum number of arrows pointing at a construct, at a minimum of 110 responses determined to be the sample size of the study.

It is superlative to investigate the entire population in research on an argument that the population is almost finite, however it not possible (53). Therefore, the right choice for the elements of the sample to make it representative of the population is important. As propounded by Gall, Gall, and Borg (54), convenient sampling was chosen for this research since the respondents (i.e. general public) are naturally occurring, readily available (55), and have less complexity to conduct the research.

\section{Data collection and analysis}

A survey is a widely used data collection method in quantitative research (56) which allows a researcher to collect a sizeable amount of data economically (57). It is one of the popular and common data collection methods in business and management studies (58); (57)) that is easy to administer because people are familiar with the survey mechanism (41). According to Burton (59), the survey is also very useful in testing hypotheses that analyze relationships between constructs present in quantitative research. As far as this research is concerned, the primary data collection method will be an Internet-based survey. This is because the use of internet-based web survey is highly accepted and more popular $((60) ;(61))$ in comparison to the traditional practice of mail or telephone $((62) ;(63))$ and common approach for the population of the study which is geographically diverse (61). This method also provided an advantage of increased flexibility to tailor the questionnaire, global reach, ease of data analysis, time-saving in reaching the potential respondents apart from providing quick, inexpensive, efficient, and accurate information concerning population $((61) ;(64))$. Sekaran (65) precisely posits that attitudes, opinions, 
and practices can be best measured through a questionnaire. Therefore, an online web-based survey was designed to facilitate data collection in this research.

The trend of using SEM in social sciences in the evaluation of predictors and criterion relationship has been on a growing trend (66). According to Aktepe, Ersöz, and Toklu (67), SEM can explain the association between the variables. Hence, it is found to be a powerful statistical technique in assessing a measurement model and a structured model (68). Therefore, PLS-SEM which is mainly considered for prediction purposes was used to test the proposed model's predictive potential and model quality (52). This study has taken an extended analysis by performing a multigroup analysis to differentiate the findings between two groups (i.e. Ayurvedic Medicine Users and Ayurvedic Medicine Non-Users). Tests such as bootstrapping, blindfolding, multigroup analysis, and permutation were used to predict the relevant indicators for the research.

\section{Results}

\section{Research sample analysis}

The data originate from a survey conducted among Malaysians. 291 respondents consist of $29.9 \%$ male respondents and $70.1 \%$ of female respondents participated and rated their responses about various aspects of Ayurvedic Medicine. The research sample analysis is shown in Table 3.

Table 3: Research Sample Analysis

\begin{tabular}{|l|l|c|c|}
\hline Characteristics & Category & Frequency & $\mathbf{( \% )}$ \\
\hline Gender & Male & 87 & 29.9 \\
\hline Age & Female & 204 & 70.1 \\
& $18-24$ & 198 & 68.0 \\
& $25-34$ & 39 & 13.4 \\
& $35-44$ & 32 & 11.0 \\
& $45-54$ & 17 & 5.8 \\
\hline \multirow{5}{*}{ AM Usage } & $55-64$ & 4 & 1.4 \\
& $65-74$ & 1 & 0.3 \\
\hline & Users & 85 & 29.2 \\
& Non-Users & 206 & 70.8 \\
\hline
\end{tabular}

In order to ensure that the differences between users and non-users of Ayurvedic Medicine are evaluated, a specific question was included in the survey requesting the participants to indicate their usage of Ayurvedic Medicine. As expected, only 29.2\% of respondents are using Ayurvedic Medicine. This separation was undertaken to perform a Multigroup Analysis to evaluate the differences between these two groups in the consumption of Ayurvedic Medicine.

\section{Measurement model assessment}

A measurement model can be clearly distinguished between a formative and reflective model by performing a Confirmatory Tetrad Analysis (CTA) in PLS-SEM (69). The rule of thumb to be followed are as shown in Table 4:
Table 4: Confirmatory Tetrad Analysis Rule of Thumb

\begin{tabular}{|l|c|c|c|}
\hline & $\begin{array}{c}\text { Confident } \\
\text { Intervals } \\
\text { Low adj }\end{array}$ & $\begin{array}{c}\text { Confident } \\
\text { Intervals Up } \\
\text { adj }\end{array}$ & $\begin{array}{c}\text { Measurement } \\
\text { Model } \\
\text { Classification }\end{array}$ \\
\hline If all values are & + & + & Formative \\
\hline If all values are & - & - & Formative \\
\hline If all values are & - & + & Reflective \\
\hline
\end{tabular}

A CTA was performed to determine the type of measurement model of the study. The result shows the entire values for Confident Intervals Low adj. to be negative and Confident Intervals Up adj. to be positive. Hence, it was ascertained that the measurement model under study is reflective.

In order to perform a measurement model assessment, a PLS path model analysis was performed. Several items were omitted since the loadings were below threshold levels. Figure 2 shows the path diagram of the study.

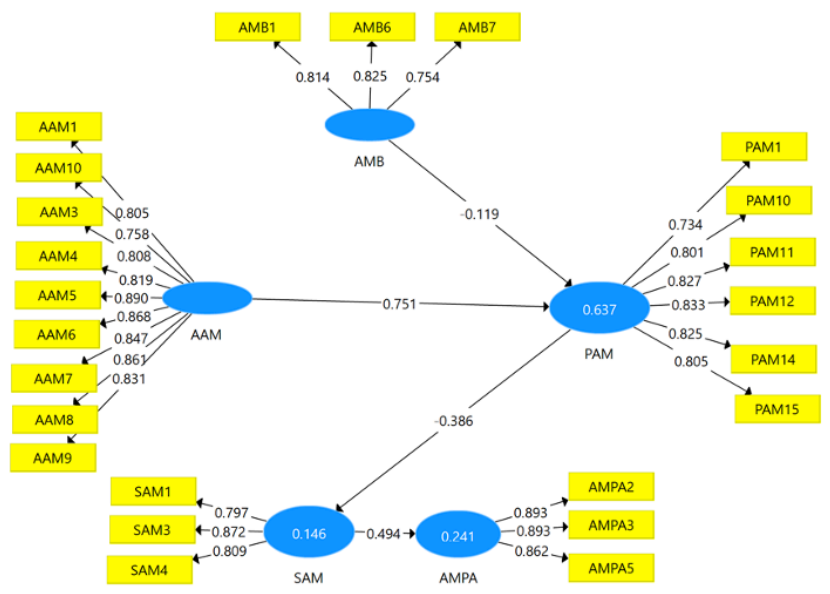

Figure 2: Structural Model

Some scholars (e.g. (70); (71); (72)) recommended several criteria to be met for the measurement model assessment. Commonly accepted indicators include items factor loadings (FL), composite reliability (CR), and Average Variance Extracted (AVE). The rules of thumbs as shown in Table 5 are used in assessing these criteria.

Table 5: Construct Loadings, Validity, and Reliability

\begin{tabular}{|l|c|l|}
\hline Indicator & Threshold & Author \\
\hline FL & $>0.708$ & Hair et al (72) \\
\hline CR & $>0.800$ & Henseler \& Sarstedt (73) \\
\hline AVE & $>0.500$ & Fornell \& Larcker (74)
\end{tabular}

The results are shown in Table 6 .

Table 6: Construct Loadings, Validity, and Reliability

\begin{tabular}{|c|c|c|c|c|c|}
\hline Construct & $\begin{array}{c}\text { Min } \\
\text { Loading }\end{array}$ & $\begin{array}{c}\text { Max } \\
\text { Loadings }\end{array}$ & $\begin{array}{c}\text { Cronbach's } \\
\text { Alpha }\end{array}$ & CR & AVE \\
\hline AMB & 0.754 & 0.825 & 0.714 & 0.840 & 0.637 \\
\hline AAM & 0.758 & 0.890 & 0.944 & 0.953 & 0.693 \\
\hline PAM & 0.734 & 0.833 & 0.891 & 0.917 & 0.648 \\
\hline SAM & 0.797 & 0.872 & 0.768 & 0.866 & 0.683 \\
\hline AMPA & 0.862 & 0.893 & 0.858 & 0.914 & 0.779 \\
\hline
\end{tabular}


As shown in Table 6, the factor loadings ranged between 0.734 and 0.893 . On the other hand, CR and AVE values were well above the recommended threshold and therefore, it was concluded that all indicators for measurement model assessment have been met.

\section{Constructs Discriminant Validity}

In order to ascertain discriminant validity, three approaches were used: i. indicators' cross loading as recommended by Hair et al (72), ii. Fornell and Larcker (74) criterion and iii. Heterotrait- Monotrait (HTMT) Ratio of correlation. The results are shown in Table 7, Table 8, and Table 9 respectively.

Table 7: Cross-Loadings among Constructs

\begin{tabular}{|c|c|c|c|c|c|}
\hline Construct & AMB & AAM & PAM & SAM & AMPA \\
\hline AMB1 & $\mathbf{0 . 8 1 4}$ & -0.275 & -0.305 & 0.407 & 0.375 \\
\hline AMB6 & $\mathbf{0 . 8 2 5}$ & -0.235 & -0.285 & 0.442 & 0.386 \\
\hline AMB7 & $\mathbf{0 . 7 5 4}$ & -0.307 & -0.306 & 0.363 & 0.410 \\
\hline AAM1 & -0.364 & $\mathbf{0 . 8 0 5}$ & 0.730 & -0.399 & -0.324 \\
\hline AAM3 & -0.253 & $\mathbf{0 . 8 0 8}$ & 0.641 & -0.217 & -0.254 \\
\hline AAM4 & -0.303 & $\mathbf{0 . 8 1 9}$ & 0.617 & -0.289 & -0.272 \\
\hline AAM5 & -0.326 & $\mathbf{0 . 8 9 0}$ & 0.697 & -0.386 & -0.300 \\
\hline AAM6 & -0.259 & $\mathbf{0 . 8 6 8}$ & 0.673 & -0.205 & -0.215 \\
\hline AAM7 & -0.275 & $\mathbf{0 . 8 4 8}$ & 0.671 & -0.264 & -0.260 \\
\hline AAM8 & -0.265 & $\mathbf{0 . 8 6 1}$ & 0.697 & -0.248 & -0.242 \\
\hline AAM10 & -0.330 & $\mathbf{0 . 8 3 1}$ & 0.628 & -0.320 & -0.228 \\
\hline PAM1 & -0.174 & $\mathbf{0 . 7 5 8}$ & 0.562 & -0.175 & -0.132 \\
\hline PAM10 & -0.341 & 0.621 & $\mathbf{0 . 7 3 7}$ & -0.328 & -0.273 \\
\hline PAM11 & -0.293 & 0.623 & $\mathbf{0 . 7 9 7}$ & -0.333 & -0.266 \\
\hline PAM12 & -0.346 & 0.610 & $\mathbf{0 . 8 2 6}$ & -0.281 & -0.279 \\
\hline PAM14 & -0.329 & 0.691 & $\mathbf{0 . 8 2 6}$ & -0.377 & -0.321 \\
\hline PAM15 & -0.253 & 0.661 & $\mathbf{0 . 8 0 9}$ & -0.225 & -0.212 \\
\hline SAM1 & 0.418 & -0.225 & -0.223 & $\mathbf{0 . 8 0 1}$ & 0.435 \\
\hline SAM3 & 0.422 & -0.322 & -0.372 & $\mathbf{0 . 8 7 1}$ & 0.437 \\
\hline SAM4 & 0.416 & -0.283 & -0.347 & $\mathbf{0 . 8 0 6}$ & 0.353 \\
\hline AMPA2 & 0.409 & -0.228 & -0.262 & 0.425 & $\mathbf{0 . 8 9 4}$ \\
\hline AMPA3 & 0.433 & -0.246 & -0.302 & 0.452 & $\mathbf{0 . 8 9 3}$ \\
\hline AMPA5 & 0.455 & -0.322 & -0.345 & 0.432 & $\mathbf{0 . 8 6 2}$ \\
\hline & & & & & \\
\hline
\end{tabular}

Table 8: Square Root of the Average Variance Extracted (AVE) (In Bold) and Correlations between Constructs (Off-Diagonal)

\begin{tabular}{|c|c|c|c|c|c|}
\hline Construct & AMB & AAM & PAM & SAM & AMPA \\
\hline AMB & $\mathbf{0 . 7 9 8}$ & & & & \\
\hline AAM & 0.343 & $\mathbf{0 . 8 3 3}$ & & & \\
\hline PAM & 0.375 & 0.793 & $\mathbf{0 . 8 0 5}$ & & \\
\hline SAM & 0.506 & 0.337 & 0.384 & $\mathbf{0 . 8 2 6}$ & \\
\hline AMPA & 0.490 & 0.300 & 0.344 & 0.495 & $\mathbf{0 . 8 8 3}$ \\
\hline
\end{tabular}

Table 9: Summary of HTMT Results

\begin{tabular}{|c|c|c|c|c|}
\hline Construct & AMB & AAM & PAM & SAM \\
\hline AAM & 0.413 & & & \\
\hline PAM & 0.468 & 0.460 & & \\
\hline SAM & 0.685 & 0.389 & 0.457 & \\
\hline AMPA & 0.625 & 0.330 & 0.391 & 0.608 \\
\hline
\end{tabular}

An examination of indicators' cross-loading provided adequate evidence that no indicator loads higher on an opposing construct (refer to Table 7). Additionally, Table 8 provided sufficient support that each construct's AVE is greater than its squared correlation with the remaining constructs. The results of HTMT ranged between 0.330 and 0.685 . Henseler et al.
(2016) explained that the HTMT score should be between the confidence interval value of -1 and 1 to achieve discriminant validity. Hence, the HTMT criterion has been fulfilled as well.

Therefore, it was concluded that all analyses exhibit discriminant validity and provide adequate support for the measures' reliability and convergent validity. Given the aftereffects of the two methods, discriminant validity has been established for the measurement model and therefore, the outer measurement model found to be reliable and valid. Consequently, the measurement model is fit to estimate the parameters in the inner structural model.

\section{Structural model assessment}

Structural model assessment which outlines one or more relationships linking the hypothesized model's construct requires fulfillment of several criteria including i. assessment of collinearity issue (VIF value $<4.0$, Hair et al., 2014), ii. assessment of the path coefficient (significant employing bootstrapping technique, Chin, 2010), iii. assessment of the level of $\mathrm{R}^{2}$ $\left(\mathrm{R}^{2}\right.$ value $>0.10$, Falk \& Miller, 1992), iv. assessment of effect size $f^{2}\left(f^{2} \geq 0.15\right.$-moderate effect size, $f^{2} \geq$ 0.35-large effect, Cohen, 1988), and v. assessment of predictive relevance $\mathrm{Q}^{2}\left(\mathrm{Q}^{2}>0\right.$, Hair et al., 2011).

The analysis indicated that all items' VIF values were below 4.0, hence, the collinearity issue was not present in the structural model. Next, the path coefficient was examined. The results are shown in Table 10 below.

\section{Table 10: Summary of Path Coefficient and t- Statistics Results}

\begin{tabular}{|l|c|c|c|c|c|c|}
\hline Constr & \multicolumn{2}{|c|}{ PAM } & \multicolumn{2}{c|}{ SAM } & \multicolumn{2}{|c}{ AMPA } \\
\hline uct & $\boldsymbol{\beta}$ & t-value & $\boldsymbol{\beta}$ & t-value & $\boldsymbol{\beta}$ & t-value \\
\hline AMB & 0.119 & $3.187^{* * *}$ & & & & \\
\hline AAM & 0.751 & $22.346^{* * *}$ & & & & \\
\hline PAM & & & 0.386 & $7.775^{* * *}$ & & \\
\hline SAM & & & & & 0.494 & $10.812^{* * *}$ \\
\hline
\end{tabular}

Notes: t-values at $* * *$ significance at 0.01 .

Assessment of path coefficients employing a bootstrapping technique indicates all paths to be significant at a p-value of 0.01 . Additionally, it has also fulfilled the suggestion by Hair, Ringle, and Sarstedt (2011) that a coefficient value of at least 0.1 must be obtained to prove the existence of an impact on a structural model.

Next the coefficient of determination, $\mathrm{R}^{2}$ was examined. The results are reported in Figure 3. PAM, SAM and AMPA reported an $\mathrm{R}^{2}$ (adjusted $\mathrm{R}^{2}$ ) value of $64.0 \%(63.7 \%), 14.9 \%(14.6 \%)$ and $24.4 \%$ (24.1\%) respectively.

Table 11: Summary of Effect Size $\left(f^{2}\right)$ Results

\begin{tabular}{|l|r|r|r|}
\hline Construct & PAM & \multicolumn{1}{|c|}{ SAM } & \multicolumn{1}{|c|}{ AMPA } \\
\hline AMB & 0.134 & & \\
\hline AAM & 1.390 & & \\
\hline PAM & & 0.173 & \\
\hline SAM & & & 0.324 \\
\hline
\end{tabular}


Table 11 provides the results of $f^{2}$. Based on Cohen's (1988) guidance, the constructs under study reported a moderate effect size in explaining the endogenous variables.

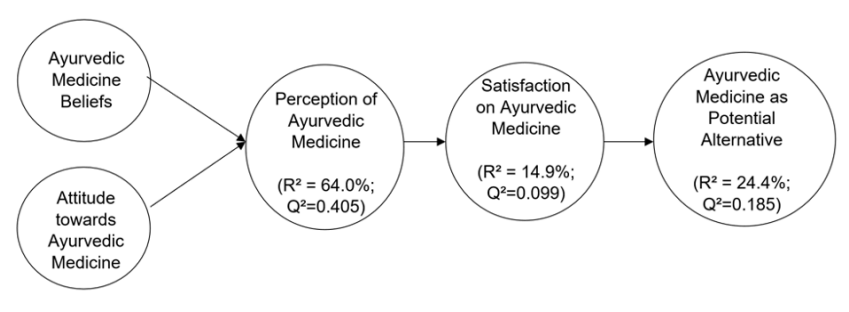

Figure 3: Structural Model

Finally, the assessment of predictive relevance, $\mathrm{Q}^{2}$ performed. The results of the analysis are presented in Figure 3. PAM, SAM and AMPA reported a $\mathrm{Q}^{2}$ value of $0.405(40.5 \%), 0.099(9.9 \%)$ and $0.185(18.5 \%)$ respectively. These scores are well above zero as recommended by Hair et al (2011). This provides sufficient predictive relevance of the structural model (Esposito Vinzi, et al., 2010), allowing predictions of the endogenous latent variables' indicators.

In addition to the $\mathrm{Q}^{2}$ assessment, Shmueli et al. (2016) proposed a set of procedures to evaluate the predictive performance of the structural model. It is based on k-fold cross-validated prediction errors and prediction error summaries statistics. A sample size of more than 100 is recommended to use 10 folds in PLS predict test. Several statistics such as the root mean squared error (RMSE), the mean absolute error (MAE), and the mean absolute percentage error (MAPE) are used to assess the predictive performance. Nevertheless, RMSE alone is found to be sufficient to evaluate predictive relevance. When the RMSE scores of PLS are more than Linear Modelling (LM) scores, the structural model is said to have strong predictive relevance. Mixed results of RMSE PLS scores and LM scores can be considered to have moderate predictive relevance. Table 12 reports the results of the PLSPredict test.

Table 12: RMSE and LM Statistics RMSE

\begin{tabular}{|c|c|c|c|c|} 
& & \multicolumn{3}{|c|}{ RMSE } \\
\hline PAM1 & 0.619 & & LM & $\mathbf{Q}^{2}$ \\
\hline PAM10 & $\mathbf{0 . 5 6 9}$ & $<$ & 0.641 & 0.379 \\
\hline PAM11 & 0.608 & $<$ & $\mathbf{0 . 5 6 7}$ & $\mathbf{0 . 3 9 9}$ \\
\hline PAM12 & 0.603 & $<$ & 0.615 & 0.373 \\
\hline PAM14 & 0.543 & $<$ & 0.619 & 0.381 \\
\hline PAM15 & 0.570 & $<$ & 0.554 & 0.482 \\
\hline SAM1 & $\mathbf{0 . 6 3 4}$ & $>$ & 0.577 & 0.428 \\
\hline SAM3 & $\mathbf{0 . 5 5 9}$ & $>$ & $\mathbf{0 . 6 0 0}$ & $\mathbf{0 . 0 7 2}$ \\
\hline SAM4 & $\mathbf{0 . 5 6 8}$ & $>$ & $\mathbf{0 . 5 3 5}$ & $\mathbf{0 . 1 2 2}$ \\
\hline AMPA2 & $\mathbf{0 . 5 2 2}$ & $>$ & $\mathbf{0 . 5 3 7}$ & $\mathbf{0 . 0 9 9}$ \\
\hline AMPA3 & $\mathbf{0 . 5 3 5}$ & $>$ & $\mathbf{0 . 5 0 8}$ & $\mathbf{0 . 0 5 5}$ \\
\hline AMPA5 & $\mathbf{0 . 5 3 3}$ & $>$ & $\mathbf{0 . 5 0 2}$ & $\mathbf{0 . 0 7 9}$ \\
\hline
\end{tabular}

The results indicate that about $60 \%$ of the items have a higher RMSE score for PLS in comparison to LM. Hence, it is concluded that the structural model understudy has moderate predictive relevance.

\section{Multigroup analysis}

Next, a Multigroup Analysis (MGA) was performed to examine the differences between the users and non-users of Ayurvedic Medicine. Before performing MGA, CR and AVE were examined to ensure that it has met the requirements of the structural model. As shown in Table 17, both groups (i.e. Ayurvedic Medicine Users and Ayurvedic Medicine Non-Users) have fulfilled CR and AVE requirements for each construct under study.

While using PLS-SEM, establishing the invariance of measures is important to avoid misleading group comparisons. In order to address this concern, Henseler et al. (2016) introduced a three-step approach to measure measurement invariance of composite models (MICOM). This procedure requires an assessment of step 1: configural invariance, step 2: compositional invariance, and step 3: the equality of composite mean values and variances.

Step 1 was established while running MICOM in Smart PLS since it automatically establishes configural invariance. Next, step 2, compositional invariance was examined. This step requires that the original correlation value be compared with $5 \%$ quantile. The compositional invariance is said to be established only when the original correlation value equals to or greater than the $5 \%$ quantile value. The results are shown in Table 13.

Table 13: Compositional Invariance Test Results

\begin{tabular}{|c|c|c|c|}
\hline Construct & $\begin{array}{c}\text { Original } \\
\text { Correlation }\end{array}$ & $\mathbf{5 \%}$ Quantile & Result \\
\hline AMB & 1.000 & 0.999 & Yes \\
\hline AAM & 0.996 & 0.957 & Yes \\
\hline PAM & 0.999 & 0.996 & Yes \\
\hline SAM & 0.999 & 0.997 & Yes \\
\hline AMPA & 1.000 & 0.991 & Yes \\
\hline
\end{tabular}
compositional invariance condition since the original correlation values are more than $5 \%$ quantile values. Hence, step 2 fulfilled the composition invariance requirements.

Steps 3 requires that mean original difference and variance original difference falls between its respective $2.5 \%$ and $97.5 \%$ boundaries. When both conditions are met, it is will serve as evidence of "full invariance (FI)". If only one of the conditions is met, it is a reflection "partial invariance (PI)". When both conditions are unmet, then there is "no invariance (NI)",

Table 14 and Table 15 reports the results of the equality of composite mean values and variances respectively.

Table 14: Mean Composite Equality Results

\begin{tabular}{|l|r|r|r|c|}
\hline Construct & $\begin{array}{c}\text { Original } \\
\text { Difference }\end{array}$ & $2.5 \%$ & $97.5 \%$ & Result \\
\hline AMB & -1.023 & -0.257 & 0.248 & NI \\
\hline AAM & 0.798 & -0.248 & 0.252 & NI \\
\hline PAM & 0.751 & -0.245 & 0.250 & NI \\
\hline SAM & -0.952 & -0.253 & 0.258 & NI \\
\hline AMPA & -0.787 & -0.258 & 0.247 & NI \\
\hline
\end{tabular}


Shathees Baskaran et.al., Perception and Readiness towards Indian Ayurvedic Medicine Acceptance to Combat COVID-19

Table 15: Variance Composite Equality Results

\begin{tabular}{|c|c|c|c|c|} 
Construct & $\begin{array}{c}\text { Original } \\
\text { Difference }\end{array}$ & $\mathbf{2 . 5 \%}$ & $\mathbf{9 7 . 5 \%}$ & Result \\
\hline AMB & -0.327 & -0.251 & 0.223 & NI \\
\hline AAM & 0.160 & -0.359 & 0.361 & PI \\
\hline PAM & 0.088 & -0.397 & 0.349 & PI \\
\hline SAM & -0.494 & -0.320 & 0.290 & NI \\
\hline AMPA & 0.036 & -0.356 & 0.318 & PI \\
\hline
\end{tabular}

Henseler et al. (71) explained that the existence of "partial invariance" or "no invariance" situation does not allow data pooling but permits meaningful multigroup analyses and comparison. Since step 3 of MICOM's requirements have been met, a multigroup comparison was performed.

Table 16: Multigroup Comparison Test Results

\begin{tabular}{|c|c|c|c|c|c|}
\hline $\begin{array}{l}\text { Relations } \\
\text { hip }\end{array}$ & $\begin{array}{l}\text { Compari } \\
\text { son }\end{array}$ & $\begin{array}{c}p \\
\text { PLS- } \\
\text { MGA }\end{array}$ & $\begin{array}{c}p \\
\text { Para- } \\
\text { metric }\end{array}$ & $\begin{array}{c}p \\
\text { Welch- } \\
\text { Satterth } \\
\text { waite }\end{array}$ & $\begin{array}{c}p \\
\text { Permuta } \\
\text {-tion }\end{array}$ \\
\hline $\begin{array}{l}\text { AMB } \\
\text { PAM }\end{array}$ & $\begin{array}{l}\text { User vs. } \\
\text { Non- } \\
\text { User }\end{array}$ & 0.578 & 0.515 & 0.562 & 0.434 \\
\hline $\begin{array}{l}\text { AAM } \\
\text { PAM }\end{array}$ & $\begin{array}{l}\text { User vs. } \\
\text { Non- } \\
\text { User }\end{array}$ & 0.474 & 0.468 & 0.468 & 0.494 \\
\hline $\begin{array}{l}\text { PAM } \\
\text { SAM }\end{array}$ & $\begin{array}{c}\text { User vs. } \\
\text { Non- } \\
\text { User }\end{array}$ & 0.230 & 0.218 & 0.228 & 0.139 \\
\hline $\begin{array}{c}\text { SAM } \\
\text { AMPA }\end{array}$ & $\begin{array}{l}\text { User vs. } \\
\text { Non- } \\
\text { User }\end{array}$ & 0.115 & 0.144 & 0.129 & 0.113 \\
\hline
\end{tabular}

Table 16 shows the results of multigroup comparisons based on the PLS-MGA approach, the parametric approach, the Welch-Satterthwaite approach, and the permutation test. PLS-MGA analysis results do not entail different outcomes across methods used for the comparative analysis. In other words, the analysis shows that the variances do not differ across groups and generally, the multigroup comparison test results correspond very closely. This additional multimethod approach has provided enhanced confidence in the final results obtained.

\section{Hypotheses testing}

Since all conditions for assessment and structural model have been fulfilled, it was concluded that the structural model is fit to perform hypotheses testing. Hence, hypotheses testing was performed for all respondents at once as well as for each subgroup separately. Table 17 displays the results for hypotheses testing.

The bootstrap analyses using 5,000 samples show that three hypotheses (i.e. AAM PAM, PAM SAM and SAM AMPA) for both groups are significant at a p-value of 0.01. As far as AMB PAM is concerned, the hypothesis was retained at a p-value of 0.05 . Hence, it was concluded that all hypotheses formulated in the research were able to be retained. The findings provided adequate evidence that both subgroups do not differ and behave similarly to Ayurvedic Medicine's belief, perception, satisfaction, and also acceptance.
Table 17: Usage-Specific Hypotheses Testing Results

\begin{tabular}{|c|c|c|c|c|}
\hline & Indicator & Alla & Users $^{b}$ & $\begin{array}{c}\text { Non- } \\
\text { Users }\end{array}$ \\
\hline$n$ & & & 85 & 206 \\
\hline \multicolumn{5}{|l|}{ Latent Variables } \\
\hline \multirow[t]{2}{*}{ AMB } & CR & 0.840 & 0.731 & 0.827 \\
\hline & AVE & 0.637 & 0.776 & 0.614 \\
\hline \multirow{2}{*}{ AAM } & CR & 0.953 & 0.958 & 0.941 \\
\hline & AVE & 0.693 & 0.718 & 0.641 \\
\hline \multirow[t]{2}{*}{ PAM } & CR & 0.917 & 0.905 & 0.908 \\
\hline & AVE & 0.648 & 0.615 & 0.621 \\
\hline \multirow[t]{2}{*}{ SAM } & CR & 0.866 & 0.919 & 0.823 \\
\hline & AVE & 0.683 & 0.791 & 0.608 \\
\hline \multirow[t]{2}{*}{ AMPA } & CR & 0.914 & 0.913 & 0.898 \\
\hline & AVE & 0.779 & 0.779 & 0.746 \\
\hline \multicolumn{5}{|c|}{ Path Relationships } \\
\hline AMB PAM & $\mathrm{H} 1$ & $3.187 * * *$ & $0.504 * *$ & $2.388 * *$ \\
\hline AAM РAM & $\mathrm{H} 2$ & $22.346 * * *$ & $11.362 * * *$ & $19.688 * * *$ \\
\hline PAM SAM & $\mathrm{H} 3$ & $7.775 * * *$ & $3.557 * * *$ & $3.87 * * *$ \\
\hline SAM AMPA & $\mathrm{H} 4$ & $10.812 * * *$ & $3.526^{* * *}$ & $7.202 * * *$ \\
\hline
\end{tabular}

\section{Discussion}

According to multigroup analysis, users and non-users of Ayurvedic medicine are found to have no significant differences. Hence, it was concluded that both groups' variance does not differ. This can be attributed to the readily known benefits of Ayurvedic medicine as well as its cheaper cost in comparison to other modern medicines. As claimed by Gawde, Shetty, and Pawar (31) and Roy, Gupta, and Ghosh (33), knowledge about Ayurveda exists among both users and non-users. Hence, addressing factors that limit a nonuser from consuming Ayurvedic medicine such as availability of Ayurvedic physician, more transparent communication of Ayurvedic medicine efficacy validation, access to facilities providing the services, and more importantly, a reasonable disease healing duration will create stronger acceptance among nonusers.

The result provided adequate evidence to support the claim that there is a significant relationship between Ayurvedic Medicine beliefs and perceptions of Ayurvedic Medicine among the respondents (t-values significance at $p$-value $<0.01$ ). A multigroup test of the same hypothesis indicates that users and non-users of Ayurvedic medicine supported the hypothesis at a pvalue $<0.05$. Hence, it is evident that comprehension of any health-related issue is driven by the perception and also the belief systems although it may vary from culture to culture (75). Therefore, the outcome of various experimentation leads to the conclusion that the essence of their perception often affects their active and implicit responses, which then affect the circumstance to produce a repeatable and consistent result. Their basic understanding of the circumstance has been 
controlled by their set of beliefs; developed by their previous experiences. Their expectations dictated their opinions, emotions, and reactions to the situation which, in turn, influenced the situation's outcome.

A test of the relationship between attitude towards Ayurvedic Medicine and perceptions of Ayurvedic Medicine found to be significant for the entire pool of respondents as well as both subgroups at a $p$-value $<0.01$. According to sociocultural theory, the beliefs and attitude influences behaviours (76) which were further validated through Health Belief Model by Rosenstock et al (77) explaining that beliefs and attitudes are the predictors of health behaviors. Hence, Ayurvedic medicine is the view or interpretation of this alternative medicine by the user and non-users. However, the attitudes of ayurvedic medicine are closely related to perception. In line with the 1996 study by Singh and Wilkes which examines complaint behavior as a dependent variable, their study shows that complaint attitudes are well anticipated in terms of perceptual variables as an independent.

A hypothesis testing the relationship between perceptions of Ayurvedic Medicine and satisfaction on Ayurvedic Medicine was able to be retained. The hypotheses for the entire respondents and also the subgroups were found to be significant at $p$-value $<0.01$. The satisfaction of the Ayurvedic customer was generally represented by the comparison between the quality expected and the perceived. However, several marketing researchers opined that satisfaction was a direct consequence of perception. The higher the rates, the more satisfied the customer is, which corresponds to significant results. Past research investigating mental health by Dow (78) has indicated that people's intention to seek help is shaped by their perception of a given illness.

A significant relationship was found between satisfaction on Ayurvedic Medicine and Ayurvedic Medicine as a Potential Alternative for COVID-19. The hypotheses tested were able to be retained at a pvalue $<0.01$. The loyal customers are indeed more valuable to the ayurvedic industry than satisfied customers. Since loyal customers/patients visit again, recommend treatments to others, and spread positive word of mouth, and give more value to the Ayurvedic industry, which increases the potential for consideration Ayurvedic medicine as an alternative.

\section{Conclusion}

Ayurvedic Medicine is equally important for empirical investigation as modern medicine because it has its strengths. The present study examined perception and readiness towards Indian Ayurvedic Medicine consumption acceptance to combat the COVID-19 outbreak. The respondents involved in this study are 291 Malaysians above aged 18 who are users and nonusers of Ayurvedic Medicine in Malaysia. It was found that the non-users of Ayurvedic Medicine are outnumbered than the users, precisely reflecting the current scenario which may introduce the potential usage of Ayurvedic Medicine as a treatment in the future.

The study found that all the hypotheses were supported which add value to the proposition of encouraging Ayurvedic Medicine as an alternative medicine to combat the COVID-19 outbreak. Ayurvedic Medicine has its strengths in terms of perception where it is still used as an alternative treatment by many communities around the world including Malaysia. This study reveals that the belief and satisfaction towards Ayurvedic Medicine has proved its potential medicinal property to combat the COVID-19 outbreak and asserts both homeopathy and Ayurvedic Medicine practitioners to continue investigating its potential benefits and consequently recommending it as an alternative treatment.

\section{Theoretical and Practical Contributions Theoretical Contribution}

Scholarly research is scarce in explaining the phenomenon under study through an integrated model as proposed in this research, particularly in the domain of Ayurvedic Medicine. The authors' review of the literature revealed that most researches have investigated the variables considered in the study as a separate constituent empirically examining a one-to-one relationship instead of explaining the causal relationships among the variables through an integrated model in unlocking empirical evidence about the phenomenon. This stands out as a novel contribution to the study of Ayurvedic Medicine. Moreover, the current study contributes significantly to the existing knowledge of Ayurvedic Medicine exploring the public perception about Ayurvedic Medicine as a potential alternative medicine to combat the COVID-19 outbreak.

\section{Practical Contribution}

This study offers some interesting insights for the relevant stakeholders regarding the importance of public perception towards Ayurvedic Medicine as a potential treatment to combat COVID-19. Firstly, the study findings provided adequate evidence that public and private healthcare organizations should widen their horizons beyond modern medicine in defining alternative treatments for COVID-19. Secondly, considering the potential of Ayurvedic Medicine, healthcare professionals shall expose themselves to traditional complementary medicines, and acquire knowledge and skills in complementing modern medicine with traditional medicine. Thirdly, the interplay between constructs investigated in the study has provided a sequential process of promoting Ayurvedic Medicine as an alternative, beginning from the belief and attitude up to the adoption of Ayurvedic Medicine as an alternative in combating COVID-19. This insight will be useful in designing and developing health policies in creating an equivalent awareness of traditional medicine as in the case of modern medicine. The integration of both expertise may provide a swift solution to find potential treatment to combat COVID-19 based on Ayurveda resources. Besides, this study may contribute globally in terms of disseminating 
the idea of Ayurveda as a potential treatment for COVID-19, especially to the World Health Organization.

\section{Limitations}

Despite the useful insights gained, this study suffered a few limitations. Firstly, the study utilized a quantitative approach. Hence, comprehension of attitudes, beliefs, and perceptions are limited to quantitative assessments. Secondly, this study was a cross-sectional design, limiting the ability to address the changes in attitude, perception, beliefs, and satisfaction over time. Hence, it does not enable reaching firm inferences for a phenomenon that is evolving continuously over time. Thirdly, the scope of the research is confined to Malaysia, a country with little adoption of Ayurvedic Medicine. Hence, generalization outside the scope of the study may not be valid. Hence, generalization about the issue should be done with careful attention.

\section{Recommendations for future research}

In order to address the limitations of the current study, several options are recommended. Firstly, a mixed-method approach is recommended to triangulate the findings to provide more conclusive evidence. Secondly, a longitudinal study can be employed to evaluate the variations over time and to identify the coherence of the responses. Thirdly, since the rate of adoption of Ayurvedic Medicine differs significantly across the countries, identification of moderator and mediator variables in facilitating examination of the proposed causal relationships may provide much deeper insights into understanding the general publics' attitude, belief, perception, and satisfaction about Ayurvedic Medicine and its adoption.

\section{Financial support}

This research did not receive any specific grant from funding agencies in the public, commercial, or not-for-profit sectors.

\section{Declaration of Competing Interests}

No competing interest

\section{Acknowledgements}

Not applicable

\section{References}

1. Yoshida Y, Rashid MH, Yoshida Y, Alim MA. Perceptions of Ayurvedic medicine by citizens in Dhaka, Bangladesh. Nagoya Journal of Medical Science 2016; 78: 99-107.

2. Patwardhan B. Strengthening the ayurveda ecosystem. Journal of Ayurveda and Integrative Medicine 2016a; 7: 73-75.

3. Patwardhan B. Strategic cooperation with WHO. Journal of Ayurveda and Integrative Medicine 2016; 7(1): $1-2$.

4. Colley FC. Traditional Indian medicine in Malaysia. Journal of the Malaysian Branch of the Royal Asiatic Society 1978; 51(1): 77-109.
5. Kritikaa SR, Paul Antony KP. Perceptions towards Ayurvedic tourism. International Journal of Pure and Applied Mathematics 2018; 119(18): 3587-3600.

6. Rastogi S, Pandey DN, Singh RH. COVID-19 Pandemic: A pragmatic plan for Ayurveda Intervention. Journal of Ayurveda and Integrative medicine, 2020; S0975-9476(20)30019-X.

7. Philips CA, Augustine P, Rajesh S, Madhu D. Complementary and Alternative Medicine-related Drug-induced Liver Injury in Asia. Journal of Clinical and Translational Hepatology 2019; 7(3): 263-274.

8. Tabish SA. Complementary and Alternative Healthcare: Is it Evidence-based? International Journal of Health Sciences 2008; 2(1): 5-9.

9. Jaiswal YS, Williams LL. A glimpse of AyurvedaThe forgotten history and principles of Indian traditional medicine. Journal of traditional and complementary medicine 2017; 7(1): 50-53.

10. Posada E. The Ayurveda Natural Medicine System and Its Environmental Implications. Environmental Science: An Indian Journal 2017; 13(4): 144.

11. Raj S, Karthikeyan S, Gothandam KM. Ayurveda-A glance. Research in Plant Biology 2011; 1(1): 1-14.

12. Mishra L, Singh BB, Dagenais S. Ayurveda: A historical perspective and principles of the traditional healthcare system in India. Alternative Therapies in Health and Medicine 2001; 7(2): 36-42.

13. Nilashi M, Samad S, Yusuf SYM, Akbari E. Can complementary and alternative medicines be beneficial in the treatment of COVID-19 through improving immune system function? Journal of Infection and Public Health 2020; 13(6): 1-3.

14. Wynn SG, Fougère BJ. Veterinary herbal medicine. Saint-Louis (Mo): Mosby; 2007.

15. Yi Y, Lagniton P, Ye S, Li E, Xu RH. COVID-19: what has been learned and to be learned about the novel coronavirus disease. International Journal of Biological Sciences 2020; 16(10): 1753-1766.

16. Engler S. Science' vs. "religion" in classical Ayurveda. Numen, 50, Koninklijke Brill NV, Leiden, The Netherlands; 2003.

17. Koch A. Wie medizin und heilsein wieder verwischen. Ethische plausibilierungsmuster des Ayurveda im Westen. Zeitschrift F"ur Medizinische Ethik 2006; 52(2): 169-182.

18. Berger R. Ayurveda Made Modern: Political Histories of Indigenous Medicine in North India, 1900-1955. Springer; 2013.

19. Chopra I, Kamal KM. A systematic review of the quality of life instruments in long-term breast cancer survivors. Health and quality of life outcomes 2012; 10(1): 14.

20. Ben-Arye E, Schiff E, Vintal H, Agour O, Preis L, Steiner M. Integrating complementary medicine and supportive care: patients' perspectives toward complementary medicine and spirituality. The Journal of Alternative and Complementary Medicine 2012; 18(9): 824-831. 
21. Sumathipala K, Radcliffe E, Sadler E, Wolfe CD McKevitt C. Identifying the long-term needs of stroke survivors using the International Classification of Functioning, Disability and Health. Chronic illness 2012; 8(1): 31-44.

22. Maddux JE, Lewis J. Self-efficacy and adjustment. In Self-efficacy, adaptation, and adjustment (pp. 37-68). Springer, Boston, MA; 1995.

23. Narahari SR, Aggithaya MG, Morrow SE, Ryan TJ. Developing an integrative medicine patient care protocol from the existing practice of Ayurveda dermatology. Current Science 2016; 111(2): 302-317.

24. Armstrong GM, Kotler P, Harker M, Brennan R. Marketing: an introduction. Pearson UK; 2018.

25. Sathiyaseelan T, Gnanapala WKAC. Service Quality and Patients' Satisfaction on Ayurvedic Health Services. American Journal of Marketing Research 2015; 1(3): 158-166.

26. Mehrotra R, Bajaj S, Kumar D. Use of complementary and alternative medicine by patients with diabetes mellitus. The National Medical Journal of India 2004; 17(5): 243-245.

27. Panchal GS, Mehta AS, Panchal JR, Balat JD, Nair G. Knowledge, attitude and practice of nonmedicinal alternative therapy in general population of Ahmedabad, India. Journal of Clinical \& Experimental Research 2014; 2(2): 115-120.

28. Mankar NN, Zad VR, Agharia MM, Sawant SD, Bansode AA. Knowledge, Attitude and Practices towards Ayurvedic Medicine use among Second Year MBBS Students. Journal of Evolution of Medical and Dental Sciences 2015; 4(2): 223-227.

29. Bhalerao MS, Bolshete PM, Swar BD, Bangera TA, Kolhe VR, Tambe MJ, Wade MP, Bhowate SD, Sonje UB, Gogtay NJ, Thatte UM. Use of and satisfaction with complementary and alternative medicine in four chronic diseases: A cross-sectional study from India. The National Medical Journal of India 2013; 26(2): 75-78.

30. Gallinger Z, Bressler B, Devlin SM. A survey of perceptions and practices of complementary alternative medicine among Canadian gastroenterologists. Canadian Journal of Gastroenterology and Hepatology 2014; 28(1): 45-49.

31. Gawde SR, Shetty YC, Pawar DB. Knowledge, attitude, and practices toward Ayurvedic medicine use among allopathic resident doctors: A cross sectional study at a tertiary care hospital in India. Perspectives in Clinical Research 2013; 4(3): 175-180.

32. Thatte UM, Rege NN, Phatak SD, Dahanukar SA. The flip side of Ayurveda. Journal of Postgraduate Medicine 1993; 39: 179-82.

33. Roy V, Gupta M, Ghosh RK. Perception, attitude and usage of complementary and alternative medicine among doctors and patients in a tertiary care hospital in India. Indian Journal of Pharmacology 2015; 47(2): 137-142.
34. Johnson B, Christensen L. Educational research: Quantitative, qualitative, and mixed approaches. Thousand Oaks, CA: Sage Publications; 2008.

35. Khalid K, Hilman H, Kumar KM. Get along with quantitative research process. International Journal of Research in Management 2012; 2(2): 15-29.

36. Snider J. Commentary. The cult of statistical pyrotechnics. Education Week 2010; 29(21): 20-21.

37. Lind DA, Marchal WG, Wathen SA. Statistical Techniques in Business \& Economics (13th edition). USA: McGraw-Hill; 2008.

38. Salmon MH. Introduction to Logic and Critical Thinking, 5th edition. Thomson Wadworth; 2007.

39. Cooper DR, Schindler PS. Business Research Methods. (9th edition). USA: McGraw-Hill; 2006.

40. Creswell JW. Research Design: Qualitative, Quantitative, and Mixed Methods Approaches. (4th Edition.). Thousand Oaks, California: SAGE Publications. Inc; 2014.

41. Fraenkel JR, Wallen NE. How to design and evaluate research in education (6th Edition.). New York, NY: McGraw-Hill; 2006.

42. Ashraf M, Saeed H, Saleem Z, Rathore HA, Rasool F, Tahir E, Bhatti T, Khalid, J, Bhatti, I, Tariq A. A cross-sectional assessment of knowledge, attitudes and self-perceived effectiveness of complementary and alternative medicine among pharmacy and nonpharmacy university students. BMC Complementary and Alternative Medicine 2019; 19(1); 95.

43. Neuman WL. Social Research Methods: Qualitative and Quantitative Approaches. 3rd ed, Boston, Allyn and Bacon; 2004.

44. Fowler FJ. Survey research methods, Newbury Park, CA, SAGE; 2002.

45. Lowhorn GL. Qualitative and Quantitative Research: How to Choose the Best Design. Presented at Academic Business World International Conference. Nashville, Tennessee; 2007.

46. Ary D, Jacobs L, Razavieh A. Introduction to Research. 6th Edition, Wadsworth, Belmont; 2002

47. Roscoe JT. Fundamental Research Statistics for the Behavioral Sciences. (2nd Ed.). New York: Holt, Rinehart and Winston; 1975.

48. Malhotra NK. Marketing Research: An Applied Orientation. 5th ed., Upper Saddle River, NJ: Prentice-Hall; 2007.

49. Hair JF, Black WC, Babin BJ, Anderson RE. Multivariate Data Analysis. (7th Edition. Prentice Hall, Upper Saddle River, New Jersey; 2010.

50. Chin WW, Marcolin BL, Newsted PR. A partial least squares latent variable modeling approach for measuring interaction effects: Results from a Monte Carlo simulation study and an electronic-mail emotion/adoption study. Information Systems Research 2003; 14: 189-217.

51. Cohen J. Statistical Power Analysis for the Behavioural Science (2nd Edition) Hillsdale, NJ: Lawrence Erlbaum Associates; 1988. 
52. Hair JF, Hult GTM, Ringle C, Sarstedt M. A primer on partial least squares structural equation modeling (PLS-SEM). Sage Publications; 2014.

53. Etikan I, Musa S.A, Alkassim RS. Comparison of Convenience Sampling and Purposive Sampling. American Journal of Theoretical and Applied Statistics 2016; 5(1): 1-4.

54. Gall MD, Gall JP, Borg WR. Educational research: An introduction. Boston: Pearson Education; 2007.

55. Abrams LS. Sampling 'hard to reach' populations in qualitative research: The case of incarcerated youth. Qualitative Social Work. Research and Practice 2010; 9(4): 536-550.

56. Gupta B, Mukhopadhyay A. Local funds and political competition: Evidence from the National Rural Employment Guarantee Scheme in India. ESID Working Paper No. 42. Manchester, UK: University of Manchester; 2014.

57. Saunders M, Lewis P, Thornhill A. Research methods for business students. 4th ed. London: Prentice Hall; 2007.

58. Ghauri R, Gronhaug K, Kristianslund I. Research methods in business studies: a practical guide. US: Prentice Hall; 1995.

59. Burton D. Research Training for Social Scientists: A Handbook for Postgraduate Researchers. London, SAGE; 2000.

60. Porter SR, Whitcomb ME. The Impact of Contact Type on Web Survey Response Rates. Public Opinion Quarterly 2003; 67(4): 579-588.

61. Dillman DA. Mail and Internet surveys: The tailored design method. Hoboken, NJ: John Wiley \& Sons; 2007.

62. Couper MP. Web Surveys: A Review of Issues and Approaches. Public Opinion Quarterly 2000; 64: 464-494.

63. Atif A, Richards D, Bilgin A. Estimating NonResponse Bias in a Web-based Survey of Technology Acceptance: A Case Study of Unit Guide Information Systems. 23rd Australasian Conference on Information Systems, Geelong; 2012.

64. Marta-Pedroso C, Freitas H, Domingos T. Testing the Survey Mode Effect on Contingent Valuation Data Quality: A Case Study of Web Based Versus In-Person Interviews. Ecological Economics 2007; 62: 388-398.

65. Sekaran U. Research Methods for Business: A Skill Building Approach, 4th Edition: Wiley India Pvt. Limited; 2006.
66. Kooij DTAM, van Woerkom M, Wilkenloh J, Dorenbosch L, Denissen JJ. Job crafting towards strengths and interests: the effects of a job crafting intervention on person-job fit and the role of age. Journal of Applied Psychology 207; 102(6): 971-981.

67. Aktepe A, Ersöz S, Toklu B. Customer satisfaction and loyalty analysis with classification algorithms and Structural Equation Modeling. Computers and Industrial Engineering 2015; 86: 95-106.

68. Kline R. Principles and practices of structural equation modeling ( $2 \mathrm{n}$ Edition.). New York: Guilford Press; 2005.

69. Gudergan SP, Ringle CM, Wende S, Will A. Confirmatory Tetrad Analysis in PLS Path Modeling, Journal of Business Research 2008; 61(12): 1238-1249.

70. Chin WW. Commentary: Issues and opinion on structural equation modeling. MIS Quarterly 1988; 22(1): 7-16.

71. Henseler J, Hubona G, Ray PA. Using PLS path modeling in new technology research:updated guidelines. Industrial Management \& Data Systems 2016; 116(1): 2-20.

72. Hair JF, Hult GTM, Ringle CM, Sarstedt M. A primer on partial least squares structural equation modeling (PLS-SEM) (2 ed.). Thousand Oaks, CA: Sage; 2017.

73. Henseler J, Sarstedt, M. Goodness-of-fit indices for partial least squares path modeling. Computational Statistics 2013; 28(2): 565-580.

74. Fornell C, Larcker DF. Evaluating structural equation models with unobservable variables and measurement error. Journal of Marketing Research 1981; 18(1): 39-50.

75. Choudhry FR, Mani V, Ming L, Khan TM. Beliefs and perception about mental health issues: A metasynthesis. Neuropsychiatric Disease and Treatment 2016; 12: 2807-2818.

76. Vygotsky L. Thought and Language. Cambridge, MA: The MIT Press; 1986.

77. Rosenstock IM, Strecher VJ, Becker MH. Social learning theory and the health belief model. Health Education Quarterly 1988; 15(2):175-183.

78. Dow HD. Migrants' mental health perceptions and barriers to receiving mental health services. Home Health Care Management \& Practice 2011; 23(3):176-185. 